\title{
O Risco de Suicídio no Contexto da Atenção Psicossocial: Ensaio Psicanalítico
}

El Riesgo de Suicidio en el Contexto de la Atención Psicosocial: Ensayo Psicoanalítico

The Risk of Suicide in the Context of Psychosocial Attention: Psychoanalytic Essay

\author{
Jéssica Prudente \\ Universidade Federal do Rio Grande do Sul Rio Grande do Sul/Brasil \\ Sandra Djambolakdjian Torossian \\ Universidade Federal do Rio Grande do Sul Rio Grande do Sul/Brasil
}

\begin{abstract}
Declaração de Direito Autoral
A submissão de originais para este periódico implica na transferência, pelos autores, dos direitos de publicação impressa e digital. Os direitos autorais para os artigos publicados são do autor, com direitos do periódico sobre a primeira publicação. Os autores somente poderão utilizar os mesmos resultados em outras publicações indicando claramente este periódico como o meio da publicação original. Em virtude de sermos um periódico de acesso aberto, permite-se o uso gratuito dos artigos em aplicações educacionais e científicas desde que citada a fonte conforme a licença CC-BY da Creative Commons.
\end{abstract}

\section{Resumo}

A partir da experiência e da escuta de sujeitos em sofrimento no contexto dos Centros de Atenção Psicossocial (CAPS), tomando a Psicanálise como referência, traçamos relações entre o desamparo e sua atualização como risco de suicídio, atravessado pelo infantil. A proposta metodológica sustentase na escrita da clínica a partir do ensaio, com inspiração na construção de caso clínico. Apontam-se direções para a escuta, no trabalho em equipe, considerando-se os processos transferenciais e a transformação do "risco" em "marca".

Palavras-chaves: Risco de suicídio, Desamparo, Psicanálise, Atenção Psicossocial.

\section{Resumen}

A partir de la experiência de escucha de sujetos en sufrimiento en el contexto de los Centros de Atención Psicosocial (CAPS), com el Psicoanálisis como referencia, trazamos relaciones entre el desamparo y su actualización como riezgo de suicídio, atravesado por lo infantil. La propuesta metodológica se sostiene en la escritura clínica del caso a partir del ensayo, con inspiración en la construcción del caso clínico. Se señalan direcciones para la escucha en el trabajo com equipos, considerando los procesos transferenciales y la transformación del "riesgo/razgo" en "marca".

Palabras claves: Riezgo de suicídio, Desmparo, Psicoanálisis, Atención Psicosocial.

\begin{abstract}
From the experience and listening to suffering subjects in the context of the Psychosocial Care Centers (CAPS), referenced on Psychoanalysis, we draw relationships between helplessness and its updating as a risk of suicide, crossed by the Infanctile. The methodological proposal is based on the clinic writing and it is inspired by clinical case constructions. Listening within teamwork is pointed out as an important direction considering the transferential processes as well as the transformation of "risk" into "brand".
\end{abstract}


Keywords: Risk of suicide, Helplessness, Psychoanalysis, Psychosocial Attention.

\section{Introdução}

O campo das políticas públicas como espaço para as práticas psicológicas é bastante recente em nosso país. A Reforma psiquiátrica inicia-se na década de 70 sendo o primeiro CAPS (Centro de Atenção Psicossocial) inaugurado, em São Paulo em 1986 (Ribeiro, 2004). O espaço social, os movimentos, a história e a política interrogaram os campos do saber, abrindo brechas nas especialidades, inclusive na Psicanálise.

A entrada da Psicanálise neste âmbito acontece, principalmente, a partir da Reforma Psiquiátrica. Este movimento, na esteira da Reforma Sanitária e do processo de democratização do país, foi propondo mudanças nos modos de cuidado e de atenção à saúde, potencializando processos de desinstitucionalização da loucura e aproximando comunidade, universidade, política, meios de comunicação e as instituições (Neto, 2011). A partir destas construções é que este percurso ganhou abrangência, ou seja, nas condições de possibilidade da clínica nas políticas públicas. Sobre esta prática clínica desdobram-se as questões deste estudo, referentes à experiência da escuta psicanalítica em situações de risco de suicídio num CAPS do Rio Grande do Sul.

Escutar. Eis um exercício que pode ser entendido como uma experiência. Para além de ouvir um relato, que concerne ao estrito sentido da audição, a escuta clínica pode colocar outros modos de atenção, transformando palavras em experiências. De acordo com o sentido atribuído por Foucault (1994), experiência remete àquilo do qual se sai transformado, diferente do que foi simplesmente vivido, do tempo que foi passado (Foucault, 1994; Ortega, 1999).
As questões abordadas no presente ensaio situam-se no contexto da experiência clínica no espaço das políticas públicas, especificamente na política de saúde mental. É desde o lugar da clínica psicanalítica em um CAPS em um município do Rio Grande do Sul, acompanhando usuários adolescentes e adultos em sofrimento, que se pretende problematizar alguns temas da clínica psicanalítica, bem como a prática clínica nestes serviços. Para isso serão organizadas vinhetas clínicas de diferentes escutas realizadas.

Colocam-se como questões norteadoras deste estudo 1) Quais as relações entre o desamparo, o infantil e o risco de suicídio? 2) Quais as contribuições da escuta psicanalítica para os casos de "risco de suicídio" nos CAPS?

Primeiramente, será apresentado o conceito de "desamparo" discutido por Joel Birman (2006), a partir de textos clássicos de Freud. Após, problematiza-se, a partir de vinhetas clínicas, como esse desamparo se manifesta de modo defensivo nas demandas de "risco de morte", atravessado pelo infantil e pela via da pulsão, em adolescentes e adultos.

Como direção da escuta desses casos de risco de suicídio trabalha-se a possibilidade de tomar o "risco" como "marca" (Rodulfo, 2004), produtora de subjetividade. Coloca-se, ainda, uma breve reflexão sobre a prática clínica nos CAPS e seus efeitos. Enfatiza-se a reprodução de um modelo que não enlaça as produções dos modos de vida naquele determinado território com a história singular do sujeito, considerando apenas generalizações das estruturas psicopatológicas, o qual deve ser constantemente tensionado. Entendemos que a discussão sobre a condição de desamparo vai além da história singular, 
atualizando-se na equipe e na dinâmica institucional.

Sigmund Freud em seu texto "O malestar na civilização" escrito em 1930, propôs uma virada naquilo que, até então, constituía o objeto da psicanálise: a "cura" a partir do método da associação livre. Freud se deslocou entre polos opostos, pois inicialmente acreditava na possibilidade de uma harmonia entre o registro do sujeito e o do social (Birman, 1998). Em seguida isto foi colocado em questão, pois "a problemática do desamparo do sujeito no campo social foi a marca decisiva da leitura daquele [Freud] sobre a inserção do sujeito na modernidade" (Birman, 1998. p. 125). Enuncia-se, então, a condição de desamparo da subjetividade no social e o discurso freudiano assume um estilo trágico de leitura da modernidade (Birman, 1998).

Nesse texto, Freud declara que não há possibilidade de conciliação entre o homem e a natureza, e que o preço da vida civilizada é alto do ponto de vista psíquico. Para Freud (1930/2010), o mal-estar é constitutivo do sujeito:

O sofrer nos ameaça a partir de três lados: do próprio corpo, que, fadado ao declínio e à dissolução, não pode sequer dispensar a dor e o medo, como sinais de advertência; do mundo externo, que pode se abater sobre nós com forças poderosíssimas, inexoráveis, destruidoras; e, por fim, das relações com os outros seres humanos. O sofrimento que se origina desta fonte nós experimentamos talvez mais dolorosamente que qualquer outro [...]. (p. 31).

Joel Birman (2006), a partir das construções freudianas, problematiza o conceito de desamparo como estruturante do sujeito após a modernidade. Segundo o autor "a construção da modernidade implicou a produção do desamparo, sendo este o malestar fundamental sublinhado pelo discurso freudiano.” (Birman, 2006, p. 50).

Com a queda das grandes utopias, da religião e da tradição, que produziam um lugar definido para o sujeito e um espaço determinado a ser ocupado, o desamparo coloca-se como condição de existência.

Para problematizar o conceito de desamparo, o qual constitui uma condição estrutural do sujeito após a modernidade, Birman (2006) traz a ideia de servidão voluntária juntamente com a definição de masoquismo em Freud. $\mathrm{O}$ autor sustenta que perante o desamparo os sujeitos poderão valerse do masoquismo como forma primordial de subjetivação.

Birman (2006) indica a posição que o masoquismo ocupa não apenas na subjetividade, como também no discurso psicopatológico. Segundo Freud (1924/2007) "é justamente pelo sofrimento propiciado que a neurose se torna mais valiosa para a tendência masoquista" (p. 111). Segue-se disso que a psicopatologia ou o sintoma podem ser entendidos como um modo "mais ou menos" bem-sucedido de se defender do mal-estar, qual seja, o desamparo. Eis o efeito do desamparo na clínica: a condição de existência do sofrimento.

$\mathrm{Na}$ experiência clínica a ser problematizada neste estudo, propomos que o modo de lidar com essa condição de desamparo estrutural pode ser compreendido como uma desvitalização entendida como depressão. Na experiência de escuta aqui analisada, constata-se que algo se repete na escuta dos sujeitos que chegaram com uma demanda de urgência em função do "risco de suicídio": uma narrativa da infância empobrecida, com poucas lembranças de afeto 
e amor, sendo que os sujeitos se enunciam muitas vezes em um lugar de objeto.

Além disso, a morte aparece como um modo de representação do sofrimento e como um destino para este: no discurso dos sujeitos cuja experiência de escuta aqui trazemos, repetem-se os significantes "vazia", "sem sentido", "sem objetivo" em relação à vida e o alívio para a angústia advêm de pensamentos suicidas. Assim, o destino e a finalidade da angústia consistem em elaborações sobre como encerrar a própria vida.

Coutinho (2010); Macedo e Werlang (2007); Siqueira (2007) discutem a problemática do suicídio e do risco de suicídio, relacionando-a com a depressão, luto, dor, trauma e laço social. Isso faz emergir, mais uma vez, a relação entre desamparo e masoquismo como modo de defesa da angústia. No que tange às vinhetas clínicas que inspiram este estudo, o conceito de infantil soma-se ao de desamparo para problematizar a atualização das questões da infância nas narrativas do adulto, pela via do inconsciente. Destacando que infantil e infância não são sinônimos, ressaltamos que:

Nas primeiras formulações psicanalíticas, infantil é um adjetivo referente a um momento cronológico da vida psíquica, o qual passa a acompanhar as experiências produtoras de sofrimento em tempos posteriores. Na etiologia das neuroses buscavam-se as experiências sexuais traumáticas ocorridas durante momentos iniciais da vida. $\mathrm{O}$ abandono dessa teoria produz um novo olhar para o infantil: ao substantivá-lo, começa a ser abordado a partir da lógica do inconsciente. Fica assim estabelecida uma relação intrínseca entre o infantil e a pulsão. (Associação Psicanalítica de Porto Alegre, 1990, p. 7-8).
Aqui se dá a relação inexorável entre o infantil e a pulsão, e por consequência, com o desamparo como condição estruturante. O conceito de infantil faz um percurso, um deslocamento, de um lugar de adjetivo, como uma descrição de um período cronológico da vida dos sujeitos, para uma posição de substantivo, pois vincula-se a lógica do inconsciente e, portanto, atemporal. Esta trajetória perfaz um desdobramento da teoria das vivências sexuais traumáticas ocorridas no início da vida. Pela lógica do inconsciente, e não cronológica, se estabelece a relação entre o infantil e a pulsão.

Se assumirmos o desamparo como condição de existência do sujeito (Birman, 2006) e o masoquismo (a partir de Freud) como modo privilegiado de sofrimento e de subjetivação, também no discurso psicopatológico, podemos afirmar que tais proposições atualizam-se na clínica de modos singulares. Para Lévy (2008), “infantil é um conceito de contorno irregular, já que é definido pelo momento de sua construção na ordem do recalque [...] pela constatação de um "não ainda" totalmente recalcado. [...] é um conjunto fragmentado e só pode ser compreendido quando localizado na história do sujeito do inconsciente de um ser falante" (p. 16). Este é um conceito que emerge na escuta do inconsciente, no percurso de um acompanhamento, só podendo ser pensado a posteriori. De acordo com Lévy (2008), “o conceito de infantil não é assim uma representação da regressão (o que supõe uma progressão), mas um ponto de vista dinâmico do momento constitutivo do aparelho psíquico da criança com a especificidade das produções que isso acarreta do ponto de vista da produção do sintoma" (p. 19).

No que tange à depressão podemos associá-la com a pulsão de morte. Freud, no texto "Além do princípio do prazer" (1920/2010), sinaliza que uma característica das pulsões consiste em uma propensão ou 
inclinação a conservação, a restabelecer um estado anterior de coisas. Assim, "o princípio do prazer pode, sob a forma de princípio de Nirvana, servir à pulsão de morte. Ou seja, o prazer seria retornar a um estado primeiro" (Sigal \& Vilutis, 2001, p. 149).

O desamparo, neste caso, assume sua face psicopatológica: a da depressão, no sentido que Maria Rita Kehl dá ao termo, e flerta constantemente com a morte. Kehl (2009) afirma que "depressão é um quadro mais próximo da clínica das neuroses do que das psicoses" (p. 14) e explica que "quando um psicanalista ou psiquiatra se refere a uma depressão psicótica ou "endógena", é bem provável que se referia a uma melancolia, não a uma depressão" (p. 14). Nas palavras de Kehl (2009):

Entendo que a posição do depressivo decorre de uma escolha, no sentido freudiano de "escolha das neuroses", que se dá no momento em que o pai imaginário se apresenta como rival da criança, no segundo tempo do atravessamento do complexo de Édipo. A escolha precoce do futuro depressivo seria a de se retirar do campo da rivalidade fálica [...] Em consequência desse recuo, ao contrário do que ocorre no percurso normal do neurótico, o depressivo defende-se mal da castração - a qual, nesse ponto da constituição do sujeito, já teria ocorrido, a partir do momento em que o discurso da mãe indica à criança o lugar que o pai ocupa diante do desejo dela. (p. 15).

\section{Ensaiando a escrita da clínica}

O percurso metodológico deste estudo conforma-se com a perspectiva de um ensaio. Trata-se de um exercício teórico que emerge na experiência da clínica, com o objetivo de problematizá-la. Destaca-se que a escrita deste ensaio e as construções neste artigo se embasam na memória e na transferência do pesquisador em relação aos casos atendidos.

A metodologia indica o caminho, o "como" será construído o percurso deste estudo, definindo as estratégias de trabalho e indicando como lidar com o problema. As perguntas partiram de um campo empírico, qual seja, a clínica psicanalítica no espaço das políticas públicas. Entretanto, esta prática necessita de ancoragens teóricas para que não se encerre no campo da intuição e da percepção apenas. É o próprio método que permite o processo sempre aberto da escuta.

O desenho metodológico conforma-se com a proposta de um "ensaio". Adorno (2003) desenvolve a ideia de uma escrita que se coloca entre a ciência e a arte como uma estratégia crítica e potente de exercício do pensamento, entrelaçando teorias, práticas, intuições e afetos. Assim, o ensaio não tem como objetivo lidar com verdades últimas, estabelecer conceitos ou teleologias. Sobre este modo de escrita, Theodor Adorno afirma (2003):

[...] Ele não começa com Adão e Eva, mas com aquilo sobre o que deseja falar; diz o que a respeito lhe ocorre termina onde sente ter chegado ao fim, não onde nada mais resta a dizer: ocupa, desse modo, um lugar entre os despropósitos. Seus conceitos não são construídos a partir de um princípio primeiro, nem convergem para um fim último. (p. 17).

Além deste desenho metodológico, outra estratégia que auxiliou no processo deste estudo é a perspectiva da "construção do caso clínico", proposta por Figueiredo (2004). Tal ideia constituiu uma inspiração nesta escrita, uma influência, mas não o desenho metodológico em si, pois não foram utilizados 
casos clínicos, mas vinhetas que visibilizaram a discussão teórica.

Nesta perspectiva, a construção do caso "é o (re)arranjo dos elementos do discurso do sujeito que "caem", se depositam com base em nossa inclinação para colhê-los, não ao pé do leito, mas ao pé da letra. Incluímos aí também as ações do sujeito, entendendo que são norteadas por uma determinada posição no discurso" (Figueiredo, 2004, p. 19). Nesta noção da construção do caso, entende-se que esta se desenvolve na transferência, pois é na relação que vai se definindo o que é possível colher do discurso do sujeito e em que posição ele se coloca em relação ao analista. Nos casos apresentados, os sujeitos se colocavam, em diversos momentos, em uma posição infantil, convocando proteção e aprovação.

Cabe destacar a perspectiva de não separação entre clínica e política, a partir da ética como uma prática. Logo, problematizar a escuta clínica nas políticas públicas permite pensar que os modos de cuidado em saúde são políticos e éticos, pois indicam concepções de vida, saúde, morte, população, sociedade, cultura, etc. Tais entendimentos modulam as práticas de gestão do cuidado e produzem modos de subjetivação. De acordo com Benevides (2005):

Isto nos obriga a discutir o plano da clínica na sua inseparabilidade da filosofia, da arte, da ciência, e, em especial, da política. E por que esse destaque da interface clínica-política? Porque aí nos encontramos com modos de produção, modos de subjetivação e não mais sujeitos, modos de experimentação/construção e não mais interpretação da realidade, modos de criação de si e do mundo que não podem se realizar em sua função autopoiética, sem o risco constante da experiência de crise. $\mathrm{O}$ que queremos dizer é que definir a clínica em sua relação com os processos de produção de subjetividade implica, necessariamente, que nos arrisquemos numa experiência de crítica/análise das formas instituídas, o que nos compromete politicamente (pp. 22-23).

Foram utilizadas vinhetas de casos clínicos, em momentos importantes dos tratamentos desenvolvidos num CAPS. Essas constituem um modo de potencializar a discussão, atualizando o lugar de origem das reflexões teóricas: a prática.

\section{Sem lugar ou entre os móveis da casa - Tânia ${ }^{1}$}

Sofá. Mesa. Cadeira. Tânia. Armário.

Quarenta e poucos anos, cabelos e voz marcante. Morava com a mãe, sem filhos nem irmãos. Tinha ideações suicidas recorrentes e histórico de tentativa de suicídio no passado. Ninguém entrava nem saia desta relação: nem pai, irmão, marido ou filho. Não conheceu o pai, não lhe foi apresentado pela mãe. $O$ filho morreu logo depois de nascer. Não teve irmãos. Separou-se do marido. As entradas de terceiros sempre foram malsucedidas.

Em uma das sessões ela diz que sua mãe sempre lhe dizia: "eu te fiz para mim", referindo-se a algo, não a alguém. Falava dessa relação como se não existisse outra possibilidade a não ser atender aos desejos de sua mãe, ser exatamente como ela queria, como um objeto imóvel e acabado, um lugar de coisa, não de sujeito. E neste lugar de objeto suas tentativas de ampliar seu modo de

\footnotetext{
1 Nome fictício para preservar o sigilo dos sujeitos envolvidos. A escolha do nome tem ligação com a mitologia grega - Thanatos - personificação da morte.
} 
relação com o Outro sempre foram acompanhadas de sofrimento.

Narrava sua infância de um modo triste, com poucos elementos lúdicos, parecendo ser um objeto que não encontrava o lugar certo na casa para agradar sua mãe. E chegou para atendimento deste modo: morando com a mãe, sentindo-se sem lugar, desejando morrer. Amor e ódio eram os dois polos desta relação, sem mediação, sem um terceiro também. Esta condição se atualizava na transferência, com demandas de demonstração de afeto, atuações, enunciados destrutivos, o que por vezes provocava a vivência de uma sensação de impotência na analista.

Maria Rita Kehl (2009) diferencia a depressão da melancolia designando a primeira no campo das neuroses e a segunda no campo das psicoses, e coloca o depressivo como um sujeito que recua diante da disputa do lugar fálico. Talvez seja por esta condição de não enfrentamento da rivalidade fálica que, ao longo de sua vida, o sujeito depressivo viva com tanto sofrimento as situações de conflito, e, algumas vezes, escolha morrer ao invés de lutar.

De braços dados com o masoquismo pode-se pensar que o desamparo coloca o sujeito depressivo ${ }^{2}$ na posição em que

\footnotetext{
2 Birman, 2006, p. 52, grifo do autor: Diante da impossibilidade do sujeito de afrontar a dor produzida pelo desamparo, surge como solução imediata e, de maneira submissa, a colagem ao outro, considerado poderoso e do qual espera proteção para os seus infortúnios. O sujeito oferece ao outro o seu corpo, e o seu psiquismo para que aquele possa gozar como queira, desde que, em contrapartida, ele lhe ofereça proteção para o desamparo. Não obstante a humilhação que tal posição possa implicar para o sujeito, este prefere isso a permanecer entregue ao seu desamparo. Pode-se entrever, por esse viés, por que as depressões assumem tal importância na atualidade, resultantes que são do pacto masoquista, realizado à custa de uma imensa humilhação da auto-estima. (nota de roda pé extensa e desnecessária, poderia ser incorporada no texto).
}

qualquer "outro" é melhor do que nada, melhor do que "nenhum outro". Esta afirmação encontra ressonância nas palavras de Birman (2006) ao considerar que:

O que está no cerne da experiência masoquista é o evitamento do desamparo, na medida em que este é vivido como terror pelo sujeito. $\mathrm{O}$ masoquismo seria uma modalidade de subjetivação mediante a qual o sujeito se submete ao outro de maneira servil [...] para fugir do horror do desamparo. Para isso, o sujeito permite que o outro possa fazer o que quiser, com o seu corpo e o seu espírito [...]. (p. 28).

Assim Tânia vivia: sufocada pela mãe, mas sem conseguir supor uma vida sem ela. Para fugir do horror do desamparo e da solidão, colocava-se de modo servil nesta relação. Entretanto, isto não significava que esta fuga não acarretasse em sofrimento. Podese dizer que seus pensamentos suicidas e suas tentativas de suicídio ocorriam quando da proximidade excessiva com a mãe. De acordo com Sigal \& Vilutis (2001, p. 147) "o suicida, ao tentar se matar, faz de tal tentativa uma agressão contra um outro que se encontra internalizado nele mesmo. $\mathrm{O}$ ataque é direcionado a um outro que foi perdido ou abandonou a pessoa e do qual ela [...] deseja vingar-se em si, tentando aniquilá-lo".

Parece, neste caso, que o único modo de se separar de sua mãe era aniquilando-a vingando-se dela em si mesma, pela via do suicídio, não da morte simbólica, e deste modo negar "eternamente" a castração. E para Tânia, isso era enunciado através do desejo de acabar consigo mesma. Era-lhe mais suportável falar sobre matar a si mesma do que separar-se de sua mãe, ainda que, no fim das contas, esta seria a mais radical das rupturas.

Nesta vinheta, também podemos pensar nesta analogia: se é o discurso da mãe que indica à criança o lugar que o pai ocupa diante do desejo dela, quando o lugar é o da 
ausência que efeitos produz? Há uma indicação de lugar, qual seja o lugar que ninguém ocupa no discurso da mãe. Talvez, esta dinâmica provoque justamente a identificação com um aniquilamento, com o vazio.

O infantil, atualizado neste sujeito adulto, conforma-se em um sofrimento onde ou não se quer perder nada, ou se perde tudo, pela via da pulsão de morte em ambos os casos, por um desejo de ausência de mal-estar. De acordo com Kehl (2009, p. 15) "ao colocar-se ante a exigência de "tudo ou nada", [os depressivos] acabam por instalar-se do lado do nada". Enuncia-se a pulsão de morte nesta escuta do inconsciente e neste desejo de não se confrontar com a separação. $O$ desejo de homeostase, de ausência de tensão é enunciado de vários modos: "quero descansar para sempre"; "não quero mais viver"; "não consigo mudar, então vou morrer".

\section{Uma menina de vinte e poucos anos... Ângela ${ }^{3}$}

Ângela chora muito, quase sempre. Transmite fragilidade, ansiedade e tristeza. Parece uma criança que se perdeu dos pais no meio de uma rua movimentada. Filha caçula de uma família com mais dois irmãos, a única que ainda mora com os pais. Não consegue trabalhar nem estudar e tem dificuldades para ficar só. Pensamentos e tentativas de suicídio a acompanham há muitos anos. Seus pais são bastante religiosos, mas ela não acredita em Deus. Ao longo dos atendimentos, nunca soube dizer o que desejava para si, dizia não ter objetivos na vida: "Meus pais tem um grande objetivo na vida: a religião. Eu não tenho nada". Um dia ela formulou um desejo: a morte.

\footnotetext{
3 Nome fictício para preservar o sigilo dos sujeitos envolvidos. A escolha do nome tem ligação com a mitologia grega - Algea - espírito feminino que trazia tristezas e lágrimas aos homens.
}

"Por que eu não posso querer morrer?", pergunta ela. "Talvez nunca tenha vivido", eu penso em silêncio. Um dia seu pai relata uma cena: diz que, no início da adolescência ela quis sair de casa, fez a mochila e disse que ia embora. Pergunto o que fez e ele reponde: "disse "vai", mas vamos assinar um termo de que tu estás indo porque quer, ninguém te mandou embora"!

Diferentemente do caso anterior, mas atualizando algumas questões semelhantes, Ângela parece perdida no mundo infantil. Tenta dar conta do desejo dois pais e não consegue. Fragilmente ensaia tentativas de movimentos para si que fracassam. Nesta angústia, deseja morrer. Parece que suas diversas tentativas de suicídio são pedidos de um olhar deste pai, para que ele diga: "não, você não vai, seu lugar é aqui", mas isso nunca acontece.

Nas repetidas vezes, suas tentativas de suicídio e seus enunciados sobre a morte são tomados pelo pai como modos pueris de chamar sua atenção. Ângela diz não conseguir ficar sozinha. Narra-se como alguém carente e insegura, necessitando da presença de "qualquer outro" ${ }^{4}$ constantemente. Muitas de suas amizades ou escolhas amorosas até o momento ocorreram neste sentido: dizia não gostar das pessoas, mas eram alguém, um "outro" the fazendo companhia, lhe dando suporte a este desamparo.

Atacar a si mesmo, destruir-se é "uma agressão contra um outro que se encontra internalizado nele mesmo" (Sigal \& Vilutis, 2001, p. 147), um outro que talvez não tenha sido "suficientemente bom". Assim como o desejo dos pais era direcionado para algo total como a religião, o seu desejo estava ligado a algo tão impenetrável e fechado como a morte. Era-lhe mais suportável falar em morrer do que pensar em possibilidades de vida para si,

4 Birman (2006) sobre a experiência masoquista (p.28), como já foi discutido neste texto. 
que não o desejo dos pais. Há aqui a aliança entre o desamparo e sua face masoquista se entrelaçando ao infantil pela pulsão de morte. Tal posição produz uma relação transferencial densa e de difícil sustentação.

\section{A direção da escuta: contribuições psicanalíticas para o risco de suicídio.}

Os CAPS constituem um lugar estratégico para o trabalho em saúde mental no qual a clínica pode ser explorada na sua potência. Entretanto, estes serviços têm repetido um modelo individualizante de escutar o sofrimento, na medida em que os casos densos e de difícil manejo, geralmente, provocam um silenciamento - e uma surdez nas equipes. Silenciamento associado à atualização do desamparo enquanto sintoma institucional. Os sujeitos que chegam com a demanda de risco de suicídio estão, antes de qualquer outra interpretação, demandando escuta. Assim, acompanhá-los neste caminho e abrir espaço para seu sofrimento é um ato terapêutico. Ocorre que sustentar a transferência implica em sustentar o olhar do outro que, na maioria dos casos aparece fora da cena. Assim, sendo reconhecido pelo Outro, o sofrimento passa a existir e pode ser escutado, não somente por um terapeuta, mas por uma equipe. Isso faz com que uma rede transferencial seja acionada e $o$ peso transferencial que costuma acompanhar estes casos seja sustentado entre vários.

Essa sustentação demanda, também, que a equipe possa colocar-se em análise. Para que o trabalho seja efetivo do ponto de vista da transferência, faz-se necessário realizar uma análise das questões e sintomas que atravessam o processo de trabalho, a partir da escuta da própria equipe. Não é incomum que a relação entre o risco de suicídio, o desamparo e o infantil, pela via da pulsão de morte, acione quem escuta de modo trágico. Entretanto, apostar no encontro com o outro na escuta clínica significa, justamente, habitar um espaço de transformação.

Para que isso seja possível propomos escutar o "risco" de suicídio como traço, rabisco, marca, enlaçando-o ao infantil. O risco transforma-se assim em traço constitutivo do sujeito.

Nas vinhetas apresentadas, o desejo de aniquilação de si não é situacional, ou seja, provocado por algum episódio ou situação específica, interna ou externa, que tenha causado desequilíbrio ou desorganização. Parece que este desejo é um modo de existir e de viver, constituindo um risco que faz uma marca, não apenas como sintoma, mas como um traço.

Ricardo Rodulfo (2004), destaca a importância de a criança construir um lugar, fazer superfície e produzir marcas. De acordo com Rodulfo (2004):

Habitar um lugar é colocar coisas próprias ali, mas o ponto é que não se faz isto sem profundas modificações subjetivas em quem as põe. $\mathrm{O}$ traçado de um risco produz um impacto estruturante no "sujeito" da operação (entre aspas, porque esta operação não se ajusta aos cânones ocidentais relativos ao par sujeito/objeto). (p.32).

A escuta nos casos de risco de suicídio precisa direcionar-se na via da construção de um lugar possível a ser habitado pelo sujeito em questão. No caso de Tânia, a possibilidade de autodestruição é uma linha de fuga para uma relação sufocante. Autodestruição que precisa ser escutada como traço, ampliando seus sentidos enunciativos para que outro sujeito possa ser produzido. Para Ângela, transformar o risco em traço é poder encontrar os rabiscos que compõem os discursos totalitários como a religião e a morte. Cabe à equipe exercitar a escuta e habitar o lugar 
proposto pelo paciente para que o desamparo possa ganhar pontos de ancoragem no Outro. Se existe risco, existem possibilidades de escritas e linhas, bem como potência para traçar outros caminhos.

\section{Referências}

Adorno, T. W. (2003). O ensaio como forma. In Adorno, W. T, Notas de Literatura I. (pp. 15-45). Tradução de Jorge de Almeida, Editora 34. Coleção Espírito Crítico.

Associação Psicanalítica de Porto Alegre APPOA (1990). Editorial Revista da Associação Psicanalítica de Porto Alegre, 1 (1), 7-8.

Benevides, R. A psicologia e o sistema único de saúde: quais interfaces? (2005). Psicologia \& Sociedade, 17 (2), 2125.

Birman, J. (2006). Arquivos do mal-estar e da resistência. Rio de Janeiro: Civilização Brasileira.

Birman, J. O mal-estar na modernidade e a psicanálise: a psicanálise à prova do social. (1998). Physis: Revista de Saúde Coletiva, 8 (1), 123-144.

Coutinho, A. H. S. de A. Suicídio e laço social. (2010). Reverso, 32 (59), 61-69.

Foucault, M. (1994). História da Sexualidade: $O$ uso dos prazeres. v. 2. 7. ed. Rio de Janeiro: Graal.

Freud, S. O mal-estar na civilização (1930). In: Freud, S. (2010). O mal-estar na civilização, novas conferências introdutórias à psicanálise e outros textos (1930-1936). São Paulo: Companhia das Letras.

Freud, S. (1920). Além do princípio do prazer. In: Freud, S. (2010). Obras completas. São Paulo: Companhia das Letras, vol. 14.

Freud, S. (1924). O problema econômico do masoquismo. In: Freud, S. (2007) Escritos sobre a psicologia do inconsciente. Rio de Janeiro: Imago, v. 3.

Kehl, M. R. (2009). O tempo e o cão: a atualidade das depressões. São Paulo: Boitempo.

Lévy, R. (2008). O infantil na psicanálise: $o$ que entendemos por sintoma na criança. Petrópolis, RJ: Vozes.

Macedo, M. M. K., \& Werlang, B. S. G. Trauma, dor e ato: o olhar da psicanálise sobre uma tentativa de suicídio. (2007). Ágora, 10 (1), 89-106.

Neto, J. L. F. (2011). Psicologia, Políticas Públicas e o SUS. São Paulo: Editora Escuta.

Ortega, F. (1999). Amizade e estética da existência em Foucault. Rio de Janeiro: Graal.

Ribeiro, S. L. (2004). A Criação do Centro de Atenção Psicossocial Espaço Vivo. Psicologia: Ciência e Profissão, 24(3).

Rodulfo, R. (2004). Desenhos fora do papel: da carícia à leitura-escrita na criança. São Paulo: Casa do Psicólogo.

Sigal, A. M.; Vilutis, I. M. de. (Orgs). (2001). Colóquio freudiano: teoria e prática da psicanálise freudiana. São Paulo: Via Lettera.

Siqueira, É. S. E. A depressão e o desejo na psicanálise. (2007). Estudos e pesquisas em psicologia, 7 (1), 68-77.

Tanis, B. (1995). Memória e Temporalidade: sobre o infantil em psicanálise. São Paulo: Casa do Psicólogo.

\section{Dados sobre os autores:}

- Jéssica Prudente: Mestre em Psicologia Social e Institucional/ UFRGS, e Doutoranda do PPG em Psicologia Social e Institucional/ UFRGS.

- Sandra Djambolakdjian Torossian: Doutora em Psicologia/UFRGS e Professora do Departamento de Psicanálise e Psicopatologia/PPG Psicanálise: Clínica e Cultura/UFRGS 